\title{
EFEK MEDIASI KEPUASAN KERJA PADA PENGARUH LINGKUNGAN KERJA TERHADAP KINERJA KARYAWAN
}

\author{
Kelvin Ramban ${ }^{1}$, Edalmen ${ }^{2}$ \\ ${ }^{1}$ Program Studi Manajemen, Fakultas Ekonomi dan Bisnis, Universitas Tarumanagara \\ Email: kelvin.115170400@stu.untar.ac.id \\ ${ }^{2}$ Program Studi Manajemen, Fakultas Ekonomi dan Bisnis, Universitas Tarumanagara* \\ Email:edalmen@fe.untar.ac.id \\ *Penulis Korespondensi
}

Masuk : 02-08-2021, revisi: 15-08-2021, diterima untuk diterbitkan : 30-08-2021

\begin{abstract}
ABSTRAK
Penelitian ini bertujuan untuk mengetahui apakah terdapat pengaruh lingkungan kerja terhadap kinerja karyawan dengan kepuasan kerja sebagai variabel mediasi pada PT Uni Gemilang Sentosa di Jakarta. Data dikumpulkan dengan menggunakan kusioner terhadap 59 responden dengan teknik sampling jenuh. Pengolahan data dilakukan dengan softwarte Smart PLS versi 3.0. Hasil penelitian ini menunjukkan bahwa lingkungan kerja dan kepuasan kerja mempunyai pengaruh yang positif dan signifikan terhadap kinerja karyawan dan kepuasan kerja memediasi pengaruh lingkungan kerja terhadap kinerja karyawan secara parsial.
\end{abstract}

Kata Kunci: lingkungan kerja, kepuasan kerja, kinerja karyawan

\section{ABSTRACT}

This study aims to determine whether there is an influence of work environment on employee performance with job satisfaction as a mediating variable at PT Uni Gemilang Sentosa in Jakarta. Data were collected using cuser on 59 respondents with saturated sampling technique. Data processing is done with Smart PLS software version 3.0. The results of this study show that the work environment and job satisfaction have a positive and significant effect on employee performance and job satisfaction mediates the influence of the work environment on employee performance in part.

Keywords: work environment, job satisfaction, employee performance

\section{PENDAHULUAN}

\section{Latar Belakang}

Sumber daya manusia sangat berpengaruh penting bagi seluruh pergerakan aktivitas organisasi dan jugak pergerakan aktivitas bisnis suatu perusahaan. Keberhasilan organisasi dalam mencapai tujuan sangat dipengaruhi oleh kinerja karyawannya. Oleh karena itu setiap perusahaan mengharapkan karyawannya dapat memiliki kinerja yang tinggi, sehingga dapat memberikan kontribusi yang optimal bagi pencapaian tujuan perusahaan. Kinerja karyawan yang baik akan membuat kinerja perusahaan secara keseluruhan menjadi baik dan sebaliknya kinerja karyawan yang buruk akan menurunkan tingkat kinerja perusahaan.

Lingkungan kerja merupakan salah satu faktor yang penting dalam meningkatkan kinerja karyawan. Lingkungan kerja diartikan sebuah segala sesuatu yang berada disekitar karyawan yang mempengaruhi dirinya dalam menjalankan dan menyelesaikan tugas-tugas yang diberikan kepadanya dalam suatu wilayah (Sofyan, 2013). Lingkungan kerja yang baik cenderung akan membuat karyawannya menjadi lebih produktif sehingga pada akhirnya akan meningkatkan kinerja karyawan tersebut. Sebaliknya, lingkungan kerja yang kurang baik akan menurunkan 
produktifitas karyawan sehingga kinerja karyawan menjadi kurang maksimal. Lingkungan kerja dikatakan baik atau sesuai apabila karyawan dapat melaksanakan kegiatan secara optimal, sehat, aman dan nyaman. Lingkungan kerja yang kurang baik dapat menuntut tenaga kerja waktu yang lebih banyak dan tidak mendukung diperolehnya rancangan sistem kerja yang efisien. Hasil penelitian dari Jason dan Kurniati (2020), Ahmad Badawi Saluy, dkk (2017) Yudiningsih dkk (2016) Sidanti (2015) dan Novita Lely Markus (2014) menunjukkan adanya pengaruh positif dan signifikan lingkungan kerja terhadap kinerja karyawan.

Pengaruh lingkungan kerja terhadap kinerja juga dapat terjadi secara tidak langsung tapi dimediasi oleh variable lain. Novita Lely Markus (2014) mencoba melihat pengaruh kepuasan kerja sebagai mediasi untuk melihat pengaruh lingkungan kerja terhadap kinerja karyawan. Hasil penelitiannya menunjukkan bahwa kepuasan kerja memediasi secara parsial pengaruh lingkungan kerja terhadap kinerja kerja karyawan. Pekerjaan yang dilakukan oleh karyawan mengharuskan adanya interaksi dengan rekan kerja, atasan, standar kinerja, peraturan serta kebijakan organisasi, kondisi kerja dan lain-lain. Ini menunjukkan bahwa terdapat pengaruh lingkungan kerja terhadap kepuasan kerja karyawan. Salah satu faktor yang mendorong kepuasan kerja adalah kondisi kerja yang mendukung. Lingkungan kerja yang dimaksud adalah segala sesuatu yang ada di sekitar karyawan yang dapat memengaruhi dirinya dalam menjalankan setiap tugas atau pekerjaan yang dibebankan kepada karyawan. Penelitian yang dilakukan oleh Jasmine dan Edalmen, (2020) Novita Lely Markus (2014) Junita Yanti Tambunan (2013) menyatakan terdapat pengaruh positif dan signifikan lingkungan kerja terhadap kepuasan kerja karyawan. Namun demikian hasil yang berbeda dilaporkan oleh Puti Intan Lasya (2013) yang menemukan bahwa tidak terdapat pengaruh signifikan lingkungan kerja terhadap kinerja karyawan.

Karyawan dengan tingkat kepuasan kerja tinggi akan menunjukkan sikap positif terhadap pekerjaan yang ia jalani atau lakukan, Sedangkan apabila seorang pekerja tidak puas dengan pekerjaanya ia akan menunjukkan sikap negatif terhadap pekerjaanya tersebut. Kepuasan kerja merupakan sikap seseorang terhadap pekerjaannya yang mencerminkan pengalaman yang menyenangkan dan tidak menyenangkan dalam pekerjaannya serta harapan-harapannya terhadap pengalaman masa depan (Yuki dan Usman, 2006). Karyawan yang puas dalam pekerjaannya akan memiliki motivasi, komitmen pada organisasi dan partisipasi kerja yang tinggi, yang pada akhirnya akan terus memperbaiki kinerja mereka, begitu juga sebaliknya. Penelitian yang dilakukan oleh Asep Qustolani (2017), Marliani (2016), Florida Dessy Putri, Sanuddin, A.M. Rosa Widjojo (2013) dan Bayu (2012) menemukan terdapat pengaruh positif dan signifikan kepuasan kerja terhadap kinerja karyawan.

PT Uni Gemilang Sentosa adalah perusahaan yang bergerak di bidang distribusi yang berlokasi di dua tempat yaitu Jl. Lenteng Agung, Jagakarsa kota Jakarta Selatan dan Jl. Pulo Nangka II Blok K, Cengkareng, kota Jakarta Barat. Profit di kedua perusahaan belakangan ini mengalami penurunan bahkan cabang perusahaan yang berlokasi Jakarta Selatan telah mengalami kerugian selama tiga tahun terakhir. Kerugian tersebur diduga dikarenakan oleh menurunnya kepuasan kerja karyawan dan perubahan lingkungan kerja sebagai dampak adanya pandemi covid-19 yang membuat penjualan perusahaan semakin menurun. Oeh karena itu, penelitian ini mencoba melihat bagaimana kepuasan kerja karyawan dapat memediasi pengaruh lingkungan kerja terhadap kinerja karyawan. 


\section{Kajian teori}

Kinerja adalah hasil atau tingkat keberhasilan seseorang secara keseluruhan selama periode tertentu dalam melaksankan tugas dibandingkan dengan berbagai kemungkinan, seperti standar hasil kerja, target atau sasaran atau kriteria yang telah ditentukan terlebih dahulu dan telah disepakati bersama. Kinerja karyawan merupakan salah satu tolak ukur dalam menilai performa para karyawan yang bekerja di suatu perusahaan. kinerja karyawan dapat dipengaruhi oleh banyak faktor baik secara internal maupun eksternal. Menurut Dessler (2006) kinerja karyawan merupakan prestasi kerja yaitu perbandingan antara hasil kerja aktual dengan standar hasil kerja yang telah ditetapkan sebelumnya oleh perusahaan. Robbins (2008) mendefinisikan kinerja sebagai suatu hasil yang dicapai oleh karyawan dalam pekerjaannya menurut kriteria tertentu yang berlaku untuk suatu pekerja Mangkunegara (2006) menjelaskan kinerja karyawan sebagai hasil kerja secara kualitas dan kuantitas yang dicapai oleh seseorang karyawan dalam melaksanakan tugasnya sesuai dengan tanggung jawab yang diberikan kepadanya Menurut Simanjutak dalam Widodo (2015). kinerja merupakan tingkatan pecapaian hasil atas tugas tertentu yang dilaksanakan. Simanjutak juga mengartikan kinerja individu sebagai tingkat pencapaian atau hasil kerja seseorang dari sasaran yang harus dicapai atau tugas yang harus dilaksanakan dalam kurun waktu tertentu. Berikut adalah indikator yang digunakan intuk menilai kinerja karyawan menurut Harbani Pasolong (2010) antara lain: a) efisiensi dalam melaksanakan pekerjaan, b) karyawan yang disiplin, c) adanya inisiatif dari karyawan, d) karyawan menyelesaikan pekerjaannya dengan teliti, e) karyawan yang memiliki kejujuran dan f) kreatifitas yang tinggi.

Lingkungan kerja dapat diartikan sebagai keseluruhan alat perkakas yang dihadapi, lingkungan sekitarnya dimana seorang bekerja, metode kerjanya sebagai pengaruh kerjanya baik sebagai perorangan maupun sebagai kelompok (Simanjuntak 2003). Afandi (2016) menyatakan bahwa lingkungan kerja adalah sesuatu yang ada dilingkungan para pekerja yang dapat mempengaruhi dirinya dalam menjalankan tugas seperti temperatur, kelembaban, ventilasi, penerangan, kegaduhan, kebersihan tempat kerja dan memadai tidaknya alat - alat perlengkapan kerja. Semua keadaan berbentuk fisik yang terdapat di sekitar tempat kerja yang dapat memengaruhi karyawan baik secara langsung maupun tidak langsung adalah lingkungan kerja. Menurut Sedarmayanti (2001) secara garis besar, jenis lingkungan kerja terbagi menjadi dua, yaitu Lingkungan kerja fisik adalah semua keadaan berbentuk fisik yang terdapat disekitar tempat kerja yang dapat mempengaruhi pegawai baik secara langsung maupun tidak langsung. dan lingkungan kerja nonfisik adalah semua keadaan yang terjadi yang berkaitan dengan hubungan kerja, baik hubungan dengan atasan, maupun hubungan dengan sesama rekan kerja ataupun hubungan dengan bawahan, Lingkungan kerja non-fisik adalah lingkungan kerja yang hanya bisa dirasakan dan tidak bisa ditangkap secara langsung oleh panca indra manusia. Lingkungan kerja meliputi semua yang ada dan mempengaruhi aktifitas kegiatan karyawan setiap hari, oleh karena itu lingkungan kerja yang baik dan nyaman akan dapat meningkatkan kinerja karyawan sebaliknya lingkungan kerja yang tidak nyaman akan menurunkan kinerja karyawan. Berikut ini adalah indikator indikator yang digunakan untuk mengukur lingkungan kerja menurut Afandi (2018), yaitu; a) penerangan lampu yang memadai, b) sirkulasi udara yang baik, c) pemilihan warna sekitar yang mendukung, d) dekorasi yang membuat suasana nyaman, e) musik yang tenang. f) suhu ruangan yang optimal dan g) ruangan yang nyaman.

Lingkungan kerja yang nyaman akan membuat karyawan semakin betah dan menyukai pekerjaannya yang akhirnya akan meningkatkan kepuasan kerja karyawan tersebut, dan begitupun sebaliknya, jika lingkungan kerja tidak nyaman dan berantakan akan membuat karyawan tidak betah berada di kantor dan membuat karyawan tersebut merasa tidak puas 
dengan pekerjaannya. Dalam konteks ini lingkungan kerja akan membawa pengaruh secara langsung maupun tidak langsung terhadap kinerja karyawan. Pengaruh tidak langsung lingkungan kerja dapat dilihat dari peran mediasi dari kepuasan kerja terhadap kinerja karyawan yang akan dibahas pada penelitian ini.

Kepuasan kerja merupakan keadaan emosional yang menyenangkan maupun tidak menyenangkan dengan para pekerja melihat pekerjaan mereka. T. Hani Handoko (2000). Jangka waktu penyelesaian merupakan pencerminan perasaan seseorang terhadap pekerjaan yang jalani. Hal ini bisa dinilai dari sikap positif karyawan terhadap pekerjaan dan segala sesuatu di lingkungannya. Menurut Robbins (2008: 179), kepuasan kerja merupakan suatu sikap umum seorang terhadap pekerjaannya. Pekerjaan mengharuskan adanya interaksi dengan rekan kerja, atasan, standar kinerja, peraturan serta kebijakan organisasi, kondisi kerja dan lain-lain. Seorang dengan tingkat kepuasan kerja tinggi akan menunjukkan sikap positif terhadap pekerjaan yang ia jalani atau lakukan, Sedangkan apabila seorang pekerja tidak puas dengan pekerjaanya ia akan menunjukkan sikap negatif terhadap pekerjaanya tersebut. Berikut ini adalah indiaktor-indikator yang digunakan untuk mengukur variabel kepuasan kerja karyawan menurut Affandi (2018) yaitu a) tanggung jawab atas tugas yang diberikan, b) kesesuaian pekerjaan dengan upah yang diberikan, c) pelatihan yang memadai, d) pengawasan yang dilakukan oleh atasan dan e) hubungan dengan karyawan lain.

Berdasarkan uraian diatas dapat disimpulkan bahwa variabel lingkungan kerja berkaitan dengan variabel kepuasan kerja, selanjutnya kepuasan kerja akan berkaitan dengan kinerja karyawan yang jika disederhanakan dapat dijelaskan seperti gambar berikut:

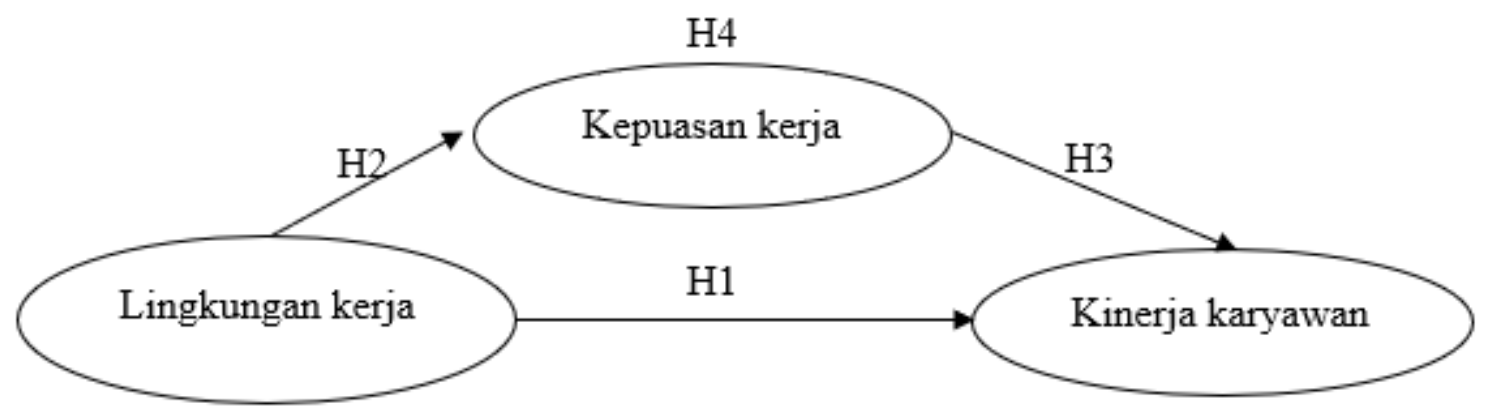

Gambar 1. Model penelitian

Berdasarkan model penelitian diatas dapat dirumuskan hipotesis sebagai berikut:

H1: lingkungan kerja memiliki pengaruh positif dan signifikan terhadap kinerja karyawan

$\mathrm{H} 2$ : lingkungan kerja memiliki pengaruh positif dan signifikan terhadap kepuasan kerja

H3: kepuasan kerja memiliki pengaruh positif dan signifikan terhadap kinerja karyawan.

H4: kepuasan kerja memediasi pengaruh lingkungan kerja terhadap kinerja karyawan

\section{METODE PENELITIAN}

Analisis data dalam penelitian ini menggunakan pendekatan Partial Least Square (PLS) dengan menggunakan aplikasi software Smart-PLS versi 3.0. Validitas konstruk diuji dengan cara melihat nilai dari convergent validity dan discriminant validity. Validitas konvergen dapat dilihat dari hasil nilai outer loadings dan average variance extracted (AVE). Nilai outer loadings dapat dikatakan valid ketika memiliki nilai > 0,7. Nilai AVE juga harus mencapai > 0,5 agar dapat digunakan (Sugiyono 2013). Reliabilitas dilihat dari hasil cronbach alpha dan nilai composite realibility. Jika nilai cronbach alpha $>0,60$ dan nilai composite realibility $>0,7$ maka kuesioner atau angket dinyatakan reliabel atau konsisten. Uji $R$-Square $\left(\mathrm{R}^{2}\right)$ digunakan untuk mengukur 
tingkat variasi perubahan variabel independen terhadap variabel dependen. Pengukuran $\mathrm{F}^{2}$ dilakukan untuk mengukur dampak dari variabel independen tertentu pada variabel dependen. Panduan dalam menilai nilai $\mathrm{f}^{2}$ adalah 0.02 untuk pengaruh yang kecil, 0.15 untuk pengaruh yang moderat, dan 0.35 untuk pengaruh yang besar. Uji $Q$-Square $\left(\mathrm{Q}^{2}\right)$ dalam hal ini adalah predictive relevance yang berfungsi untuk memvalidasi model. Nilai $\mathrm{Q}^{2}>0$ menunjukkan bahwa model mempunyai nilai predictive relevance, sedangkan nilai $\mathrm{Q}^{2}<0$ menunjukkan bahwa model kurang memiliki predictive relevance (Haryono 2017). Uji Koefisien jalur (path coefficient) menggambarkan kekuatan pengaruh antar variabel. Tanda atau arah dalam jalur harus sesuai dengan teori yang dihipotesiskan. Nilai signifikan dapat diperoleh dengan prosedur bootstrapping yang juga menghasilkan nilai t-satistik (Haryono, 2017). Uji hipotesis dinyatakan signifikan apabila variabel tersebut memiliki t-Statistic diatas tingkat signifikansi yang telah ditetapkan sebesar 1,96 dan niali P values dibawah 0,05 (Abdillah \& Hartono, 2015).

\section{HASIL DAN PEMBAHASAN}

Analisis data dilakukan melalui uji outer model dan inner model. dengan menggunakan indikator masing-masing lingkungan kerja menggunakan 7 Indikator dan kepuasan kerja menggunakan 5 indikator bersumber dari (Afandi 2018), sedangkan untuk kepuasan kerja menggunakan 7 indikator dari Harbani Pasolong (2010). Berikut adalah gambar hasil pengujian dengan analisis PLS Algorithm:

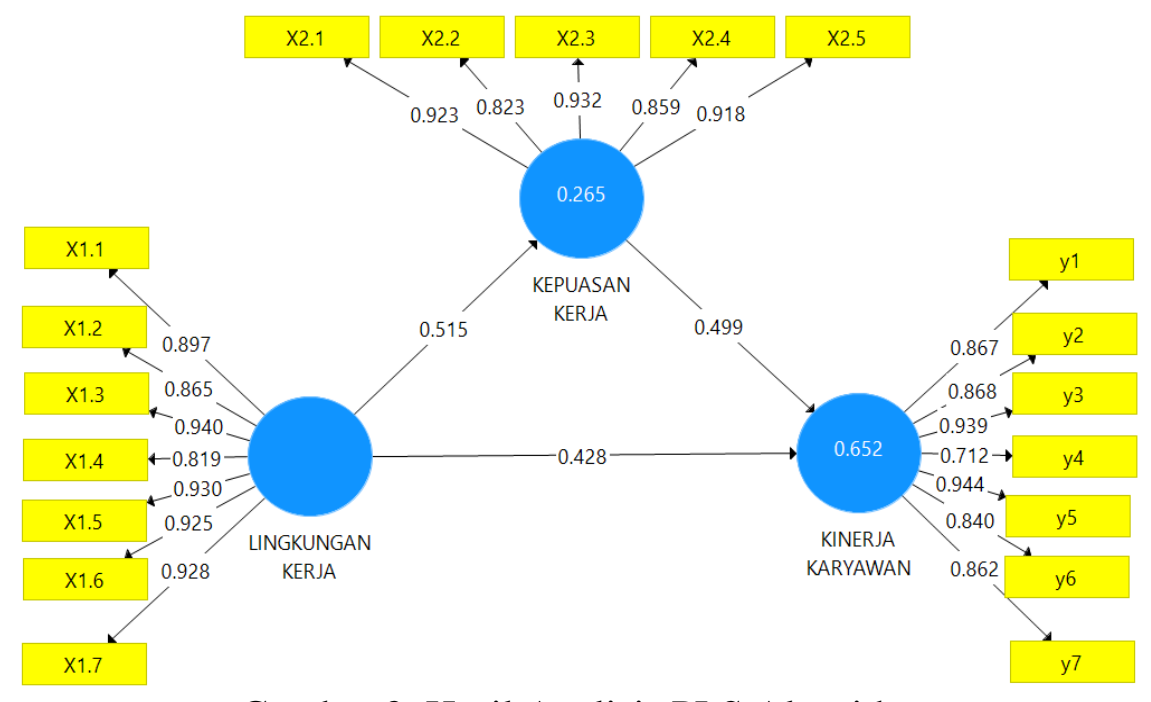

Gambar 2. Hasil Analisis PLS Algorithm

Dapat dilihat bahwa nilai loadings factor dari semua indikator yang digunakan pada setiap variabel mempunyai nilai $>0,7$ dan dapat dinayatakan valid. Perhitungan valisitas konvergen melalui AVE disajikan pada tabel berikut:

Tabel 1. Hasil analisis AVE

\begin{tabular}{|l|c|}
\hline Variabel & Nilai AVE \\
\hline Lingkungan Kerja & 0,813 \\
\hline Kepuasan Kerja & 0,795 \\
\hline Kinerja Karyawan & 0,748 \\
\hline
\end{tabular}

Dari tabel di atas dapat terlihat bahwa nilai AVE untuk semua variabel $>0,5$ dan dapat dinyatakan valid. Hasil Uji reliabilitas dengan menggunakan pendekatan cronbach alpha dan composite reliability disajikan pada table 2 yang menunjukkan bahwa indikator yang digunakan 
dalam pengukuran setiap variabel penelitian adalah reliabel, karenakan nilai cronbach alpha pada masing-masing variabel penelitian diatas 0,6 dan nilai composite reliability pada masingmasing variabel penelitian diatas 0,7 .

Tabel 2. Hasil Uji Fornell Larcker

\begin{tabular}{|l|c|c|}
\hline Variabel & Cronbach's Alpha & Composite Reliability \\
\hline Lingkungan kerja & 0,961 & 0,968 \\
\hline Kepuasan kerja & 0,942 & 0,954 \\
\hline Kinerja karyawan & 0,935 & 0,951 \\
\hline
\end{tabular}

Hasil uji $R$-Square disajikan pada Tabel 3, dapat dilihat bahwa nilai $R$ square yang terdapat dalam variabel dependen yaitu kinerja karyawan adalah sebesar 0,652 yang berarti sebesar $65,2 \%$ dari variabel dependen dapat dijelaskan oleh variabel-variabel yang diteliti dalam penelitian yaitu lingkungan kerja dan kepuasan kerja.

Tabel 3. Hasil uji $R$ square

\begin{tabular}{|l|c|}
\hline \multicolumn{1}{|c|}{ Variabel } & $\boldsymbol{R}$-square \\
\hline Kepuasan kerja & 0,265 \\
\hline Kinerja karyawan & 0,652 \\
\hline
\end{tabular}

Nilai $R$-square pada variabel mediasi yaitu kepuasan kerja yaitu sebesar 0,265 yang artinya sebesar 26,5\% dari variabel mediasi ini dapat dijelaskan oleh variabel-variabel yang diteliti dalam penelitian ini yaitu lingkungan kerja. Hasil pengujian dari variabel kinerja karyawan menunjukan adanya pengaruh yang tinggi karena memiliki nilai $R$-Square lebih dari 0,67 sedangkan pada hasil pengujian variabel kepuasan kerja memiliki pengaruh yang rendah karena memiliki nilai $R$-Square kurang dari 0,33. Hasil uji $Q$-Square ditampilkan pada table 4 berikut:

Tabel 4. Hasil Uji Q-Square

\begin{tabular}{|l|c|}
\hline \multicolumn{1}{|c|}{ Variabel } & Q-Square \\
\hline Kepuasan Kerja & 0,2 \\
\hline Kinerja Karyawan & 0,475 \\
\hline
\end{tabular}

Pada hasil pengujian predictive relevance diatas menyatakan bahwa nilai pengujian Q-Square yang terdapat dalam variabel kepuasan kerja dalam penelitian ini adalah 0,2 dan nilai pengujian Q-Square pada variabel kinerja karyawan dalam penelitian ini adalah 0,475 yang artinya model penelitian ini dapat dikatakan relevan karena memiliki nilai Q-Square yang lebih besar dari nol $\left(Q^{2}>0\right)$. Pengujian $F$-Square dapat dilihat pada Tabel 5 berikut:

Tabel 5. Tabel hasil $F$-square

\begin{tabular}{|l|c|c|}
\hline \multicolumn{1}{|c|}{ Variabel } & Kepuasan Kerja & Kinerja Karyawan \\
\hline Lingkungan Kerja & 0,36 & 0,388 \\
\hline Kepuasan Kerja & & 0,527 \\
\hline
\end{tabular}

Dari hasil tabel diatas, dapat disimpulkan bahwa a) variabel lingkungan kerja memiliki dampak yang besar pada variabel kepuasan kerja karena memiliki nilai $\mathrm{F}^{2}$ sebesar 0.36 , b) variabel lingkungan kerja memiliki dampak yang besar pada variabel kinerja karyawan yang dapat dilihat dari nilai $\mathrm{f}^{2}$ sebesar 0.388 dan c) variabel kepuasan kerja memiliki dampak yang besar pada variabel kinerja karyawan yang dapat dilihat dari nilai $\mathrm{F}^{2}$ sebesar 0.527 
Uji Hipotesis dilakukan dengan metode bootstrapping, berikut adalah gambar keluaran hasil uji bootstrapping

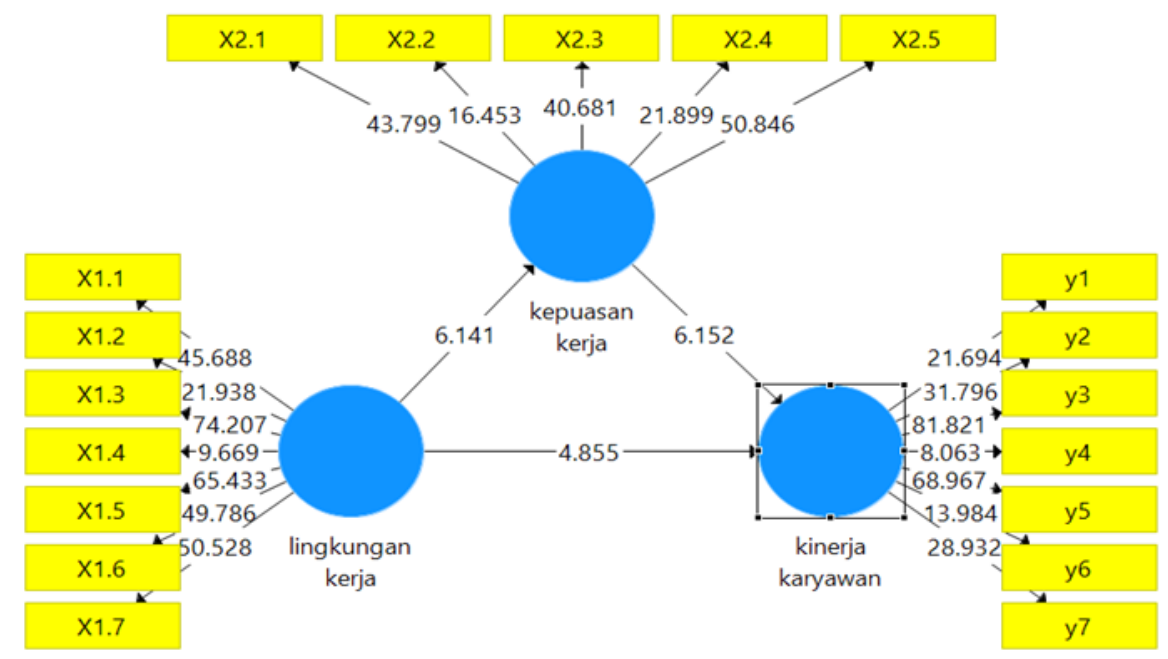

Gambar 2. Hasil uji bootstrapping

Pengujian dilakukan dengan membandingkan nilai t-statistic yang harus lebih besar dari table sebesar 1,96 dengan tingkat kepercayaan $(\alpha)$ sebesar 0,05 atau nilai $p$-value $<0,05$ (Haryono, 2017). Uji hipotesis selengkapnya ditampilkan pada table berikut:

Tabel 6. Hasil Uji Hipotesis

\begin{tabular}{|l|c|c|c|}
\hline \multicolumn{1}{|c|}{ Variabel } & Original sample & t-statistic & $\boldsymbol{p}$-values \\
\hline Lingkungan kerja $\rightarrow$ kinerja karyawan & 0,428 & 4,855 & 0,000 \\
\hline Lingkungan kerja $\rightarrow$ kepuasan kerja & 0,515 & 6,141 & 0,000 \\
\hline kepuasan kerja $\rightarrow$ kinerja karyawan & 0,499 & 6,152 & 0,000 \\
\hline Lingkungan kerja $\rightarrow$ kepuasan kerja $\rightarrow$ kinerja karyawan & 0,257 & 3,910 & 0,000 \\
\hline
\end{tabular}

Dari hasil pengujian path coefficient di atas, maka dapat dijelaskan sebagai berikut:

a. Lingkungan kerja memiliki pengaruh langsung sebesar 0,428 terhadap kinerja karyawan. Hal ini menunjukkan terdapat pengaruh positif lingkungan kerja terhadap kinerja karyawan. Nilai $t$-statistic sebesar 4,855 > 1,96 dan p-value sebesar $0,000<0,05$ menunjukkan bahwa pengaruh tersebut adalah signifikan. artinya secara statistic hipotesis 1 tidak ditolak

b. Lingkungan kerja memiliki pengaruh sebesar 0,515 terhadap kepuasan kerja. Hal ini menunjukkan bahwa lingkungan kerja memiliki pengaruh yang positif terhadap kepuasan kerja. Nilai $t$-statistic sebesar $6,141>1,96$ dan Nilai $p$ values sebesar 0,000 $<0,05$ menunjukkan pengaruhnya signifikan secara statistik artinya hipotesis 2 tidak ditolak.

c. Kepuasan kerja memiliki pengaruh sebesar 0.499 terhadap kinerja karyawan. Hal ini menunjukkan bahwa kepuasan kerja memiliki pengaruh yang positif terhadap kinerja karyawan. Nilai $t$-statistic sebesar 6,152 > 1,96 dan $p$ value $0,000<0,05$ menunjukkan bahwa pengaruhnya signifikan secara statistik artinya hipotesis 3 tidak ditolak.

d. Kepuasan kerja memediasi pengaruh lingkungan kerja terhadap kinerja sebesar 0,257 yang merupakan pengaruh tidak langsung. Dengan nilai $t$-statsistik sebesar 3, $910>1,96$ dan $p$ value sebesar $0,000<0,05$ menunjukkan bahwa kepuasan kerja memediasi secara parsial pengaruh lingkungan kerja terhadap kinerja karyawan artinya hipotesis 4 tidak ditolak. 


\section{Diskusi}

Hasil penelitian ini menunjukkan bahwa terdapat pengaruh positif dan signifikan lingkungan kerja terhadap kinerja karyawan, artinya lingkungan kerja yang semakin baik akan meningkatkan kinerja karyawan. Hasil ini sejalan dengan penelitian yang dilakukan oleh Jason dan Kurniati (2020), Ahmad Badawi Saluy, dkk (2017) Yudiningsih dkk (2016) Sidanti (2015) dan Novita Lely Markus (2014) yang juga menunjukkan adanya pengaruh positif dan signifikan lingkungan kerja terhadap kinerja karyawan. Penelitina ini juga menyimpulkan bahwa lingkungan kerja berpengaruh positif dan signifikan terhadap kepuasan kerja karyawan, artinya lingkungan kerja yang semakin baik akan meningkatkan kepuasan kerja karyawan. Hasil penelitian ini mendukung penelitian sebelumnya yang dilakukan oleh Jasmine \& Edalmen (2020), Novita Lely Markus (2014) Junita Yanti Tambunan (2013) yang juga menyatakan terdapat pengaruh positif dan signifikan lingkungan kerja terhadap kepuasan kerja karyawan. Namun hasil ini berbeda dengan penelitian Puti Intan Lasya (2013) yang menemukan bahwa tidak terdapat pengaruh signifikan lingkungan kerja terhadap kinerja karyawan.

Pengaruh kepuasan kerja terhadap kinerja karyawan dalam penelitian ini menunjukkan hasil yang positif dan signifikan, artinya kepuasan kerja yang semakin meningkat akan menyebabkan kinerja karyawan juga mengalami peningkatan. Hasil ini sesuai dengan penelitian yang dilakukan oleh Asep Qustolani (2017), Marliani (2016), Florida Dessy Putri, Sanuddin, A.M. Rosa Widjojo (2013) dan Bayu (2012) yang juga menemukan terdapat pengaruh positif dan signifikan kepuasan kerja terhadap kinerja karyawan. Terkait dengan variabel mediasi dapat dijelaskan bahwa kepuasan kerja memediasi pengaruh lingkungan kerja terhadap kinerja karyawan secara parsial. artinya dengan adanya kepuasan kerja maka pengaruh lingkungan kerja terhadap kinerja karyawan akan menjadi lebih besar. Hasil ini mendukung penelitian sebelumnya yang dilakukan oleh Novita Lely Markus (2014) yang juga memukan hasil yang sama.

\section{KESIMPULAN DAN SARAN}

Dengan selesainya penelitian ini dapat diberikan beberapa saran kepada pihak yang terkait terutama bagi PT Uni Gemilang Sentosa. Untuk meningkatkan kinerja karyawan maka lingkungan kerja harus lebih ditingkatkan, jika lingkungan kerja semakin baik maka kepuasan kerja karyawan akan meningkat dan selanjutnya akan dapat meningkatkan kinerja karyawan. Terkait dengan indikator yang digunakan untuk mengukur variabel pada penelitian ini dapat disarankan sebagai berikut, a) perlu peningkatan dekorasi ruang kantor agar lebih nyaman lagi, meskipun pemilihan warnanya sudah cukup baik, b) mengevaluasi tentang pengupahan dan tetap memberikan pelatihan yang cukup c) meningkatkan inisiatif karyawan dengan tetap memperhatikan tingkat ketelitian kerja mereka. Untuk penelitian lanjutan disarankan agar menggunakan variabel lain yang belum digunakan dalam penelitian ini misalnya kompensasi, kepemimpinan, pelatihan dan lainnya yang juga berpenaruh terhadap kinerja karyawan. Disarankan juga untuk menggunalan sampel yang lebih banyak dan jenis perusahaan yang berbeda sehingga akan dapat memperkaya literatur tentang kinerja perusahaan.

\section{REFERENSI}

Abdillah, W., \& Hartono, J. 2015. Partial Least Square (PLS) Alternatif Structural Equation Modeling (SEM) dalam Penelitian Bisinis. Yogyakarta: Andi Offset.

Afandi, P. 2016. Concept \& Indicator Human Resources Management for Management Research. Yogyakarta: Deepublish

Arifin, M. R. 2014. Pengaruh Kepuasan Kerja dan Disiplin Kerja terhadap Kinerja Karyawan PT Tri Keeson Utama Garut. Jurnal Unikom. 
Asep Qustolani “ pengaruh kepuasan kerja, keadilan procedural dan kompensasi terhadap kinerja karyawan" volume 4 No. 2 (2017)

Badawi Ahmad.2017. Pengaruh pengembangan karir, kompensasi, lingkungan kerja terhadap kinerja karyawan di CV. Sumber Baru Niaga. Magister Manajemen Universitas Mercu Buana. Jakarta

Dessler, Gary. (2006). Manajemen Sumber Daya Manusia Jilid 1. Jakarta : PT. Indeks

Handoko, T. Hani, 2008. Manajemen Personalia Sumber Daya Manusia, edisi kedua, Yogyakarta, Penerbit: BPFE.

Harianja, B. (2015). Pengaruh Lingkungan Kerja Terhadap Kepuasan Kerja Karyawan Studi Kasus pada Karyawan bagian Departemen Finishing di PT. Riau Andalan Kertas Kab. Pelalawan Provinsi Riau. Jurnal Online Mahasiswa (JOM) Universitas Riau, 2(2), 1 8.

Haryono, S. 2017. Metode SEM untuk Penelitian Manajemen AMOS Lisrel PLS. Jakarta: Luxima Metro Media.

Intan puti. 2013. Analisis pengaruh Kompensasi, kepemimpinan atasan, kesempatan promosi, dan lingkungan kerja terhadap kepuasan kerja karyawan Outsourcing Pt. Indosat Tbk. Program studi manajemen universitas bakrie. Jakarta

Isabella Jasmine \& Edalmen, 2020. Pengaruh Lingkungan Kerja Terhadap Kepuasan Kerja Dengan Motivasi Sebagai Mediasi. Jurnal Manajerial dan Kewirausahaan, Volume II No. 2/2020 Hal: 450-460 451

Jason Sebastian \& Kurniati W. Andani, 2020. Pengaruh Kompensasi Dan Lingkungan Kerja Terhadap Kinerja Karyawan PT. Bank QNB Indonesia, Jurnal Manajerial dan Kewirausahaan, Volume II No. 2/2020 Hal: 461-468

Lely Novita. 2014. pengaruh Lingkungan Kerja Terhadap Kinerja Karyawan Dengan Kepuasan Kerja Karyawan Sebagai Variabel Mediasi Pada PT Mustika Minanusa Aurora Di Kota Tarakan. Program studi manajemen universitas borneo. Tarakan

Mangkunegara, Anwar Prabu. 2009. Manajemen Sumber Daya Manusia Perusahaan. Bandung: PT Remaja Rosdakarya

Nitisemito, Alex. 1992. Manajemen Personalia: Manajemen SDM. Jakarta: Ghalia Indonesia

Nitisemito, S. 1982.Manajemen Personalia. Jakarta: Ghalia Indonesia.

Pasolong, Harbani. 2010. Teori Administrasi Publik. Alfabeta : Bandung

Robbins, Stephen P. dan Timothy A. Judge. (2008). Perilaku Organisasi Edisi ke- 12,Jakarta: Salemba Empat.

Sanuddin, Florida Dessy Putri dan A.M. Rosa Widjojo. (2013). Pengaruh Kepuasan Kerja dan Motivasi Terhadap Kinerja Karyawan PT. Semen Tonasa. EJournal Fakultas Ekonomi Universitas Atma Jaya Yogyakarta. ISSN 0852- 1875 Vol. 25 (2):217-231

Sari Marliani. 2016. Pengaruh Motivasi Kerja dan Kepuasan Kerja Terhadap Kinerja Karyawan Pada PT. Bank Negara Indonesia Cabang Karawang. Program studi manajemen ekonomi univesitas muhamadyah. Surakarta

Sedarmayanti.2011. Tata Kerja dan Produktivitas Kerja. Bandung: Mandar Maju.

Sidanti, H. 2015. Pengaruh Lingkungan Kerja, Disiplin Kerja Dan Motivasi Kerja terhadap Kinerja Pegawai Negeri Sipil di Sekretariat DPRD kabupaten Madiun.

Simanjuntak, Payaman J. 2005. Manajemen dan Evaluasi Kinerja. Jakarta : Lembaga Penerbit Fakultas Ekonomi UI.

Sofyan, Diana Khairani. 2013. Pengaruh Lingkungan Kerja Terhadap Kinerja Kerja Karyawan BAPPEDA. Malikussaleh Industrial Engineering Journal. Vol. 2 No.

Sudarmanto. 2009. Kinerja dan Pengembangan Kompetensi SDM. Yogyakarta: Pustaka Belajar Tbk. Kandatel Malang.

Sugiyono. 2017. Metode Penelitian Kuantitatif, Kualitatif, dan R\&D. Bandung: Alfabeta, CV 
Tambunan, Junita Yanti. 2012. Pengaruh Lingkungan Kerja dan Promosi Jabatan Terhadap Kepuasan Kerja Pegawai Bagian Umum Sekretariat Daerah Kabupaten Tapanuli Tengah. Program Pascasarjana. Universitas Terbuka Jakarta.

Usman, Husaini. 2006. Manajemen: teori, Praktik, dan Riset Pendidikan. Jakarta: Bumi Aksara Yudiningsih dkk. 2016. Pengaruh Lingkungan Kerja, Disiplin Kerja Terhadap Kinerja Pegawai Pada Distanak Kabupaten Buleleng.

Yulianto, E. A. 2014. Pengaruh Motivasi Kerja, Disiplin Kerja, dan Kepuasan Kerja terhadap Kinerja Karyawan RS. Asy-Syifa' Sambi. Jurnal Universitas Muhammadiyah Surakarta 